\title{
Ants' Notion of Zero through the Perception of the Absence of an Odor
}

\author{
Marie-Claire Cammaerts ${ }^{1} \&$ Roger Cammaerts $^{2}$ \\ ${ }^{1}$ Independent Researcher, Retired from the Biology of Organisms Department, University of Brussels, Belgium \\ ${ }^{2}$ Independent Researcher, Retired from the Natural and Agricultural Environmental Studies Department \\ (DEMNA) of the Walloon Region, Belgium \\ Correspondence: Marie-Claire Cammaerts, Independent Researcher, 27, Square du Castel Fleuri, 1170 Bruxelles, \\ Belgium. Tel: 32-2-673-4969. E-mail: mtricot@ulb.ac.be; mccammaerts@gmail.com
}

Received: January 3, 2019

Accepted: January 12, 2019

Online Published: January 21, 2019

doi:10.5539/ijb.v11n2p1

URL: https://doi.org/10.5539/ijb.v11n2p1

\begin{abstract}
Workers of the ant Myrmica sabuleti can acquire the notion of 'nothing', i.e. a basic concept of zero, through olfactory conditioning, the best when the odor is unpleasant (onion odor) and when the response to the absence of the odor is rewarded. With a pleasant odor (lavender, rosemary or vanilla odor), the ants learn best when the response to the odor is rewarded. To our knowledge this is the first time that olfactory operant conditioning is obtained in animals by rewarding their response to 'nothing'. The present work also points out: - the impact of the kind and quality of the cue to be learned on the animals' learning score, - the improvement of a given learning over successive similar learning experiments, - the obtaining of a better learning when the reward is associated with the animals' preference.
\end{abstract}

Keywords: Learning, Myrmica Sabuleti, Olfactory Conditioning, Operant Conditioning, Rewarding

\section{Introduction}

Comprehending the notion of zero is not an easy and frequent ability, neither for the humans nor among the animals. In the history of mankind, this concept appeared rather late in the Babylonian and the Hindu civilizations and never emerged in some civilizations, for instance those of the Romans and Greeks (Michelot, 1966). Also, the notion of zero is rather late acquired in the course of a human's life, generally after he acquired the notion of different quantities and of the numbers, i.e. after the age of four years. Among the animals, only parrots (Pepperberg, 1988, 2006; Pepperberg \& Gordon, 2005) and some monkeys (Biro \& Matsuzawa, 2001) have been proved to recognize and distinguish the zero among several amounts of elements, and the level of such a comprehension may be higher in parrots than in monkeys (loc. cit.). It is presently admitted that the concept of zero is acquired through four successive steps, a basic sensory perceptible notion, a 'different than something' notion, a quantitatively null notion, and an abstract mathematical concept of zero which can be represented by a symbol (Nieder, 2016).

We have recently shown that the ant Myrmica sabuleti Meinert 1861 can have a basic notion of nothing (zero) through operant conditioning to visual cues and their absence (M. C. Cammaerts \& R. Cammaerts 2019). However, this species uses essentially odors for navigating and uses visual cues only in the absence of useful odors (Cammaerts \& Rachidi, 2009). So, it would be logical to look if these workers could acquire the basic notion of zero through operant olfactory conditioning, i.e. conditioning to an odor and to its absence. Such a research seems to have never been done in ants, nor in any other animal species, what makes it particularly interesting. The concerned species, M. sabuleti, is a rather well known species, information having been acquired on its ecology, visual perception, angle of vision, navigation, recruitment system, visual and olfactory conditioning, ontogenesis of some of its cognitive abilities, and on the cognition of aged workers i.e. expectation of an event, use of tools, and self recognition among others (successively M. C. Cammaerts \& D. Cammaerts, 2014; M. C. Cammaerts \& R. Cammaerts, 2015a; M. C. Cammaerts \& R. Cammaerts, 2016; Cammaerts, 2018; M. C. Cammaerts \& R. Cammaerts, 2015b). It was thus appropriate to undertake a study about the acquisition of the basic notion of zero through olfactory conditioning on such a well known species.

After having explained our methods and related our results, we discuss the later then complement the bibliography about the concept of zero before concluding. 


\section{Material and Methods}

\subsection{Collection and Maintenance of Ants}

The experiments were performed on two colonies collected in an abandoned quarry of the Aise valley (Ardenne, Belgium), in September 2018. The colonies were nesting under stones and contained about 500 workers, brood and a queen. They were maintained in the laboratory in two to three glass tubes half filled with water, a cotton plug separating the ants from the water. The nest tubes of each colony were set in a tray $(34 \mathrm{~cm} \times 23 \mathrm{~cm} \times 4 \mathrm{~cm})$ which served as foraging area, and the ants received, in that area, pieces of Tenebrio molitor larvae (Linnaeus, 1758) three times per week, as well as sugar water continuously present in cotton plugged tubes. The ambient temperature was $c a 20^{\circ} \mathrm{C}$, the humidity $80 \%$, the lighting 330 lux while working on ants, and the electromagnetism $2 \mu \mathrm{Wm}^{2}$. These environmental conditions are optimum for the species. The ants are here often named 'nestmates' as researchers on social insects commonly do.

\subsection{Ants' Training}

Two small glass tubes acting as diffusers (diameter: $0.5 \mathrm{~cm}$, height: $2.5 \mathrm{~cm}$ ) were deposited in the ants' tray, one containing a source of odor, the other one being empty, the entrance of each of them being slightly plugged with loose cotton. One of these two tubes was set near the ants' food (which served as a reward), the other tube was set $12 \mathrm{~cm}$ apart the food. This design is schematized in Figure 1, upper part.

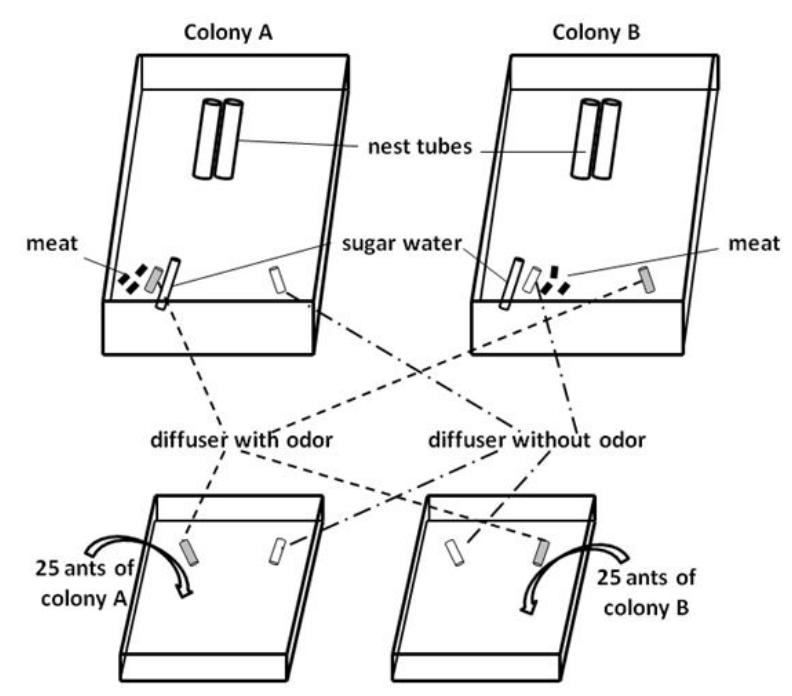

Figure 1. Experimental design and protocol

Upper part: training of the ants; six counting per day, during 4 days, of the ants present near the diffusers. Lower part: testing of the ants; 30 counting over 15 minutes of ants approaching the diffusers, during the ants' acquisition then during their loss of conditioning; the sums of these counts allowed calculating the proportions of ants giving the correct response (i.e. going near the diffusers associated with food during training). The figure represents the design of experiments 1 and 3. In experiment 2, the absence of odor was associated with food for colony A, and its presence associated with food for colony B. In experiment 4, the apparatus devoted to testing (lower part of the figure) was rotated 180 degrees (see Figure $3 \mathrm{G}, \mathrm{H}$ ).

During the ants' acquisition of conditioning (i.e. the association between a diffuser and the reward), what lasted about 4 days, the ants approaching each diffuser were counted six times per day. The mean of the six counts was established for each diffuser (= each cue) and each colony (see Tables 1-4, upper part). These numbers did not require any statistical analysis.

\subsection{Ants' Testing}

The ants of colony A and colony B were tested (without being rewarded) over their acquisition then their loss of conditioning, the ants of each colony in an own (separate) tray $(30 \mathrm{~cm} \times 15 \mathrm{~cm} \times 5 \mathrm{~cm})$ devoted to testing. These trays contained two small tubes identical to those used for training the ants, one diffusing the same odor as that used during training, the other one being empty. This design is schematized in Figure 1, lower part. Tests were 
performed each day during the ants' acquisition then loss of conditioning (so, during four, then two days). For conducting a test, 25 ants of each colony were transferred into their tray devoted to testing and containing two diffusers (= cues) identical to those used during training. At that time, the ants being in the vicinity of each diffuser were counted 30 times over 15 minutes. The sum of the counts was established for each kind of diffuser and each colony. This allowed establishing the proportion (\%) of correct responses given by each colony (see Tables 1-4, lower part). For each colony, the two obtained sums (one for each presented diffuser) were compared to the numbers expected if ants randomly went near each diffuser using the non-parametric goodness of fit $\chi^{2}$ test (Siegel \& Castellan, 1989), the level of significance being set at 0.05 .

\subsection{Experimental Planning}

A synopsis of the planning is given in Figure 2. Four successive, different, experiments were performed, the kind of odor and the location of the two diffusers differing between these four experiments One day elapsed between each of these four experiments. During the experiment 1, lavender odor was used and colony A had the diffuser of this odor located near (associated with) food while colony B had the empty diffuser associated with food. During the experiment 2 , rosemary odor was used, and colony A had the empty diffuser associated with food while colony $\mathrm{B}$ had the diffuser of rosemary odor associated with food. Lavender as well as rosemary odors are appreciated by the ants, as proved by previous observations (for lavender: M. C. Cammaerts \& D. Cammaerts, 2018; for rosemary: M. C. Cammaerts, 2017). During the experiment 3, a not pleasant odor was used, that of onion, the unpleasant character of which having been pointed in a previous work (M. C. Cammaerts \& D. Cammaerts, 2018). Colony A had the onion odor (out of a diffuser) associated with food while colony B had the empty diffuser associated with food. During the experiment 4, a potentially (never used) pleasant odor was used, that of vanilla. Colony A has the absence of odor (= the empty diffuser) associated with food while colony B had the vanilla odor (= the diffuser containing vanilla) associated with food. Until this step, the experiment 4 was similar to the experiment 2 . However, for testing the ants, the two used trays (devoted to testing and containing each one an empty diffuser and a one filled with vanilla) were $180^{\circ}$ rotated (while the diffusers set on the foraging area stayed at the same locations). This allowed checking if there was no ants' association between the relative position of the food (the reward) and any referential outside their tray (e.g. a lighting source) (see Figure $3 \mathrm{G}, \mathrm{H}$ ).

The ants' behavior in the course of these four experiments was assessed exactly identically, in the manner explained here above in the subsection 'Ants' testing'. This enabled comparing the results of the four experiments (see the 'Discussion' section).

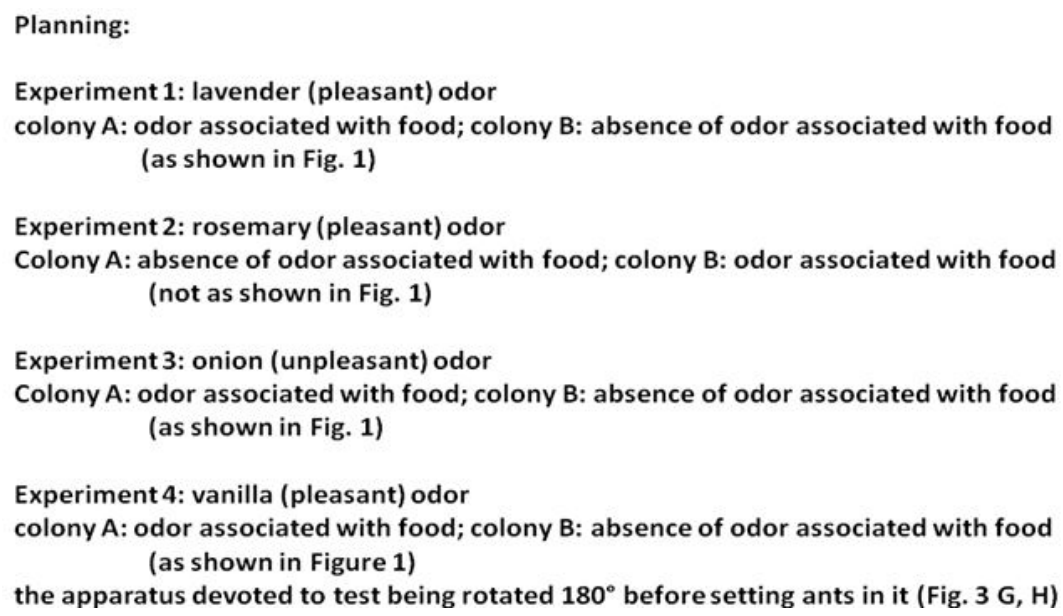

Figure 2. Synopsis of the entire experimental work

This can give a clear view of the work, and a better understanding of the methods, tables and results. 


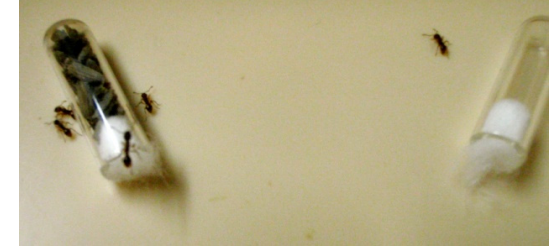

A

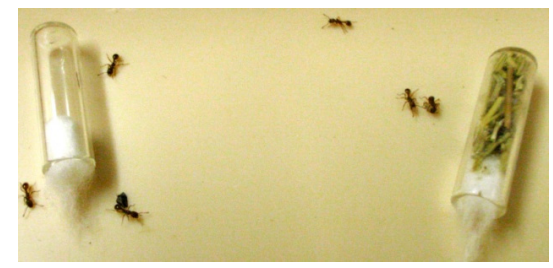

$\mathrm{C}$

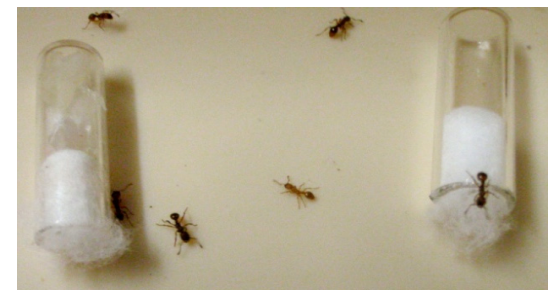

E

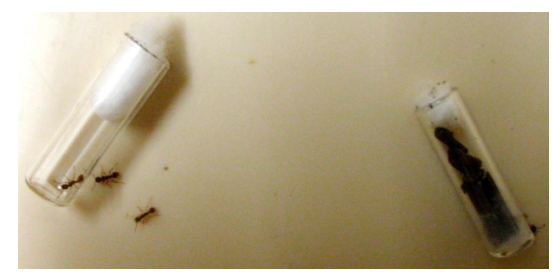

G

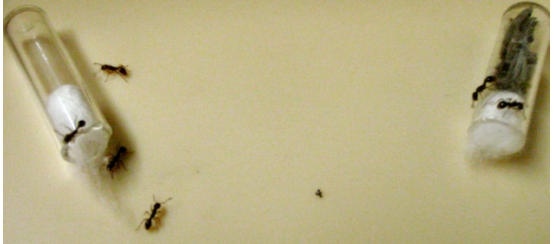

B

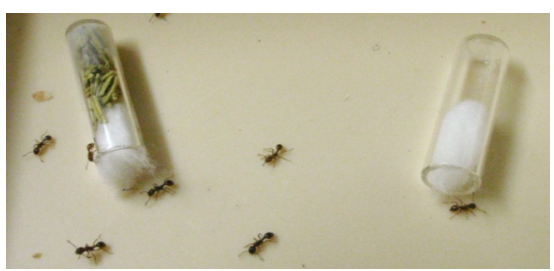

D

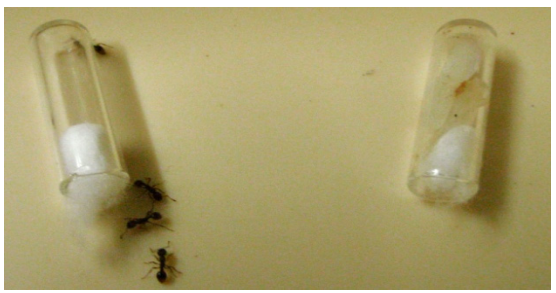

$\mathrm{F}$

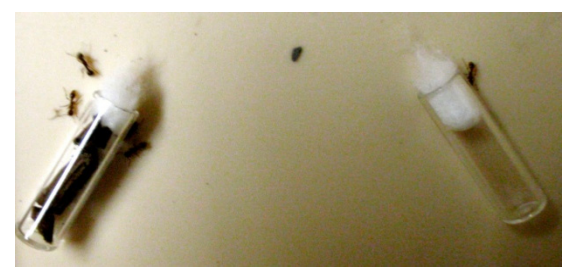

$\mathrm{H}$

Figure 3. Views of each of the four test experiments on each of the two colonies

A: ants of colony A trained to lavender odor (associated with food) vs no odor, and coming onto the odor during the test. B: ants of colony B trained to no odor (associated with food) vs lavender odor, and coming to the empty diffuser during the test. $\mathbf{C}$ : ants of colony A trained to the absence of an odor and correctly responding during the test. D: ants of colony B trained to rosemary odor and responding to that odor during the test. E: ants of colony A responding to the onion odor to which they were trained. $\mathbf{F}$ : ants of colony B responding to the absence of odor (onion is present in the right diffuser), the cue to which they were trained. Note that during this experiment, ants responded better to the absence of odor than to its presence, maybe due to the unpleasant character of the onion odor. G: ants of colony A responding to the empty diffuser, the kind of diffuser associated with the reward during training. H: ants of colony B responding to the vanilla odor which was associated with food during training.

\section{Results}

\subsection{Experiment 1, Lavender Odor Associated with Food for Colony A, No Odor Associated with Food for Colony} $B$

During training, the ants were rather numerous all around the two conditioning sites i.e. that associated with food and the other one. Of course, they were more numerous near the food. More precisely, the mean numbers of ants counted around the cues associated with food varied from 2.67 to 5.33, and those of ants counted around the other cues varied from 1.17 to 2.50 (Table 1, upper part).

Results concerning the testing experiments are given in Table 1, lower part. After 24 hours of training, the ants already went more often towards the cue associated with food during training, but this preference was not statistically significant. For colony A, 51 ants among 79 were seen near the lavender odor; they gave thus $64.56 \%$ of correct responses. However, this score did not statistically differ from that resulting from a random ants' choice 
$(39.5,39.5)\left(\chi^{2}=2.85, \mathrm{df}=1,0.05<\mathrm{P}<0.10\right)$. For colony $\mathrm{B}, 41$ ants among 68 were counted in the vicinity of the diffuser without odor; they thus reached $60.29 \%$ of correct responses. This result also did not statistically differ from that expected if ants randomly went near each presented cue $(43,34)\left(\chi^{2}=1.07, \mathrm{df}=1, \mathrm{P}=0.30\right)$. After 48 hours of training, the ants' choice of the correct response largely increased for colony A, but only slightly for colony B. Precisely, $69.41 \%$ of ants of colony A gave the correct response, what was this time statistically different from an ants' random choice $\left(\chi^{2}=5.87, \mathrm{df}=1,0.01<\mathrm{P}<0.02\right)$, but for colony $\mathrm{B}, 59.49 \%$ of the ants gave the correct response what was not different from an ants' random choice $\left(\chi^{2}=1.08, \mathrm{df}=1,0.20<\mathrm{P}<0.30\right)$. After 72 hours of training, the ants' correct responses to cues associated with food during training improved. Ants of colony A reached a highly significant score of $73.52 \%\left(\chi^{2}=24.65, \mathrm{df}=1, \mathrm{P}<0.001\right)$, and ants of colony B reached a significant score of $69.12 \%\left(\chi^{2}=4.40, \mathrm{df}=1,0.02<\mathrm{P}<0.05\right)$. After 96 hours of training, the score of the ants of colony A no longer increased, while that of ants of colony B improved. Concerning colony A, 77 ants among 111 gave the correct response, corresponding to a significant score of $69.37 \%\left(\chi^{2}=8.57, \mathrm{df}=1,0.001<\mathrm{P}<0.01\right)$. As for colony B, 50 ants among 64 gave the correct response, realizing a highly significant score of $78.13 \%\left(\chi^{2}=\right.$ 9.81, $\mathrm{df}=1,0.001<\mathrm{P}<0.01)$. The ants could thus discriminate the presence from the absence of a pleasant odor, and correctly respond to the situation associated with the reward during training. They did so more easily, more rapidly, when the cue associated with food was the presence of the odor than when the cue associated with food was its absence. After the fourth test, the two cues were removed from the ants' environment, and tests were performed over the ants' loss of conditioning.

Table 1. Results of experiment 1

\begin{tabular}{|c|c|c|c|c|c|c|}
\hline \multirow{2}{*}{$\begin{array}{l}\text { Experiment } 1 \\
\text { lavender } v s \text { no odor }\end{array}$} & \multicolumn{3}{|c|}{ Colony A } & \multicolumn{3}{|c|}{ Colony B } \\
\hline & \multicolumn{2}{|c|}{ lavender odor + food } & no odor & \multicolumn{2}{|c|}{ no odor + food } & lavender odor \\
\hline Training at & \multicolumn{6}{|c|}{ Mean numbers of ants approaching the cues } \\
\hline day 1 & & 3.83 & 1.67 & & 4.17 & 2.17 \\
\hline day 2 & & 2.67 & 2.17 & & 4.17 & 2.00 \\
\hline day 3 & & 3.50 & 2.50 & & 3.17 & 1.17 \\
\hline day 4 & & 5.33 & 2.17 & & 5.17 & 2.50 \\
\hline \multicolumn{7}{|l|}{ removal of the cues } \\
\hline Testing after & \multicolumn{6}{|c|}{ Total numbers of ants near the cues and $\%$ of correct responses } \\
\hline $24 \mathrm{~h}$ & 51 & $64.56 \%$ & 28 & 41 & $60.29 \%$ & 27 \\
\hline $48 \mathrm{~h}$ & 59 & $69.41 \%$ & 26 & 47 & $59.49 \%$ & 32 \\
\hline $72 \mathrm{~h}$ & 161 & $73.52 \%$ & 58 & 47 & $69.12 \%$ & 21 \\
\hline $96 \mathrm{~h}$ & 77 & $69.37 \%$ & 34 & 50 & $78.13 \%$ & 14 \\
\hline \multicolumn{7}{|l|}{ removal of the cues; } \\
\hline $24 \mathrm{~h}$ later & 67 & $66.34 \%$ & 34 & 43 & $66.15 \%$ & 22 \\
\hline $48 \mathrm{~h}$ later & 53 & $57.61 \%$ & 39 & 27 & $50.94 \%$ & 26 \\
\hline
\end{tabular}

Ants of colony A were trained to lavender odor associated with food (and to no odor associated with no reward), and ants of colony B were trained to no odor associated with food (and to lavender odor associated with no reward). The ants succeeded in learning the absence of a pleasant odor, doing so better after 24-72 hours when the reward was linked to the odor than when it was linked to its absence.

Twenty-four hours after the removal of the cues, the ants' response to the kinds of cues associated with food during training substantially decreased. Ants of colony A presented a score of $66.34 \%$, with 67 ants among 101 giving the correct response, a score still statistically different from that resulting from an ants' random choice $\left(\chi^{2}=4.89\right.$, $\mathrm{df}=1,0.02<\mathrm{P}<0.05)$. Ants of colony B presented a score of $66.15 \%$, with 43 ants among 65 giving the correct response, a score just under the threshold of probability when compared to that resulting from an ants' random choice $\left(\chi^{2}=2.85, \mathrm{df}=1,0.05<\mathrm{P}<0.10\right)$. The ants lost thus rapidly their olfactory conditioning to the presence as well as to the absence of an odor. Such a rapid loss of olfactory conditioning had already been revealed in a previous work on that topic (M. C. Cammaerts, Rachidi, \& D. Cammaerts, 2011). Forty eight hours after the cues removal, the ants had completely lost their conditioning. The numbers of ants counted in the vicinity of the two presented cues ( 53 and 39 for colony A, 27 and 26 for colony B) did not differ from those resulting from a random choice (colony A: $\chi^{2}=0.70, \mathrm{df}=1,0.30<\mathrm{P}<0.50$; colony $\mathrm{B}: \chi^{2}=0.01, \mathrm{df}=1,0.90<\mathrm{P}<0.95$ ). A slight difference however subsisted between the responses of ants of colonies A and B: a few ants of colony A went on giving the 
correct response while none of colony B did so. The ants having lost their conditioning to the presence or the absence of lavender odor, the following experiment could be undertaken, using rosemary odor.

\subsection{Experiment 2, No Odor Associated with Food for Colony A, Rosemary Odor Associated with Food for Colony} $B$

During training, ants visited the two sites where were set the cues, their mean numbers varying between 5.33 and 3.33 for the cue associated with food, and between 2.33 and 1.17 for the other site (Table 2, upper part).

The results obtained during testing are given in Table 2, lower part. After 24 hours of training, the ants began to preferentially move towards the diffuser associated with food during training. Concerning colony A, 50 ants among 78 gave the correct response (i.e. went to the empty diffuser), making thus a score of $64.10 \%$, what was not yet significant $\left(\chi^{2}=2.62, \mathrm{df}=1,0.10<\mathrm{P}<0.20\right)$. Concerning colony $\mathrm{B}, 43$ ants among 57 gave the correct response (i.e. went to the rosemary odor), making thus a score of $75.44 \%$, what was significant $\left(\chi^{2}=6.84, \mathrm{df}=1,0.001<\right.$ $\mathrm{P}<0.01)$. After 48 hours of training, the ants better responded to the diffuser associated with food during training. For colony A, 56 ants among 74 went to the empty diffuser, reaching thus the significant score of $75.67 \%\left(\chi^{2}=\right.$ $9.37, \mathrm{df}=1,0.001<\mathrm{P}<0.01$ ), while 65 ants of colony $\mathrm{B}$ among 92 went to the rosemary odor, making thus the significant score of $70.65 \%\left(\chi^{2}=7.36, \mathrm{df}=1,0.001<\mathrm{P}<0.01\right)$. The ants could thus learn the existence as well as the absence of an odor, doing so in 24 hours when the presence of the odor was associated with a reward, and in 48 hours when its absence was so associated. The ants' learning in the course of this experiment 2 was somewhat more rapid than their learning in the course of the previous experiment 1 . Two explanations are possible. The ants may become accustomed to learn the existence and the non-existence of an odor or the rosemary odor may be more perceived by the ants than the lavender odor. After 72 hours of training, the ants again preferentially moved towards the diffuser associated with food during training, and did so mostly when the reward was associated with the odor instead of with its absence. Indeed, 72 ants of colony A among 102 went to the empty diffuser, what was significant $\left(\chi^{2}=8.19, \mathrm{df}=1,0.001<\mathrm{P}<0.01\right)$ and corresponded to a score of $70.59 \%$, while 56 ants of colony $\mathrm{B}$ among 70 went towards the rosemary odor, a highly significant score of $80 \%\left(\chi^{2}=12.56, \mathrm{df}=1, \mathrm{P}<0.001\right)$. After 96 hours of training, the ants' proportions of correct responses no longer increased. Ants of colony A presented a score of $74.44 \%$, with 67 ants among 90 giving the correct response $\left(\chi^{2}=10.42, \mathrm{df}=1,0.001<\mathrm{P}<0.01\right)$. Ants of colony B presented a score of $76.39 \%$, with 55 ants among 72 giving the correct response $\left(\chi^{2}=9.67, \mathrm{df}=1,0.001\right.$ $<\mathrm{P}<0.01)$. The diffusers were then removed from the ants' tray.

Table 2. Results of experiment 2

\begin{tabular}{|c|c|c|c|c|c|c|}
\hline \multirow{2}{*}{$\begin{array}{l}\text { Experiment } 2 \\
\text { rosemary } v s \text { no odor }\end{array}$} & \multicolumn{3}{|c|}{ Colony A } & \multicolumn{3}{|c|}{ Colony B } \\
\hline & \multicolumn{2}{|c|}{ no odor + food } & rosemary odor & rosemary & odor + food & no odor \\
\hline Training at & \multicolumn{6}{|c|}{ Mean numbers of ants approaching the cues } \\
\hline day 1 & & 4.67 & 2.33 & & 5.33 & 1.50 \\
\hline day 2 & & 3.50 & 1.33 & & 3.33 & 1.25 \\
\hline day 3 & & 3.50 & 1.17 & & 3.50 & 2.50 \\
\hline day 4 & & 3.53 & 1.17 & & 3.33 & 2.50 \\
\hline \multicolumn{7}{|l|}{ removal of the cues } \\
\hline Testing after & \multicolumn{6}{|c|}{ Total numbers of ants near the cues and $\%$ of correct responses } \\
\hline $24 \mathrm{~h}$ & 50 & $64.10 \%$ & 28 & 43 & $75.44 \%$ & 14 \\
\hline $48 \mathrm{~h}$ & 56 & $75.67 \%$ & 18 & 65 & $70.65 \%$ & 27 \\
\hline $72 \mathrm{~h}$ & 72 & $70.59 \%$ & 30 & 56 & $80.00 \%$ & 14 \\
\hline $96 \mathrm{~h}$ & 67 & $74.44 \%$ & 23 & 55 & $76.39 \%$ & 17 \\
\hline \multicolumn{7}{|l|}{ removal of the cues; } \\
\hline $24 \mathrm{~h}$ later & 81 & $60.00 \%$ & 54 & 49 & $59.76 \%$ & 33 \\
\hline $48 \mathrm{~h}$ later & 67 & $51.54 \%$ & 63 & 53 & $55.21 \%$ & 43 \\
\hline
\end{tabular}

Ants of colony A were trained to no odor associated with food (and to rosemary odor associated with no reward), and ants of colony B were trained to rosemary odor associated with food (and to no odor associated with no reward). The ants again succeeded in learning the absence of a pleasant odor, and did again so better when the odor and not its absence were linked to the reward.

Twenty-four hours later, the ants poorly responded to the correct diffuser. Concerning colony A, 81 ants among 135 ones gave the correct response, what corresponded to a score of $60.00 \%$, and was not significant $\left(\chi^{2}=2.34\right.$, 
$\mathrm{df}=1,0.10<\mathrm{P}<0.20)$. Concerning colony $\mathrm{B}, 49$ ants among 82 ones gave the correct response, what corresponded to a score of $59.76 \%$, also not significant $\left(\chi^{2}=1.21, \mathrm{df}=1,0.20<\mathrm{P}<0.30\right)$. Thus, the ants rapidly lost their olfactory conditioning, what is usual for such a kind of conditioning (Cammaerts et al., 2011; M. C. Cammaerts $\&$ Nemeghaire, 2012; M. C. Cammaerts, 2012). Forty-eight hours after the cues removal, the ants no longer went preferentially towards the correct diffusers. For colony A, 67 among 130 ants went to the empty diffuser, making a not significant score of $51.54 \%\left(\chi^{2}=0.0154, \mathrm{df}=1,0.90<\mathrm{P}<0.95\right)$. For colony B, 53 among 96 ants went to the tube diffusing rosemary odor, making a score of $55.21 \%$, also not significant $\left(\chi^{2}=0.33, \mathrm{df}=1,0.50<\mathrm{P}<\right.$ 0.70). The following experiment could then be undertaken on these no longer conditioned ants.

\subsection{Experiment 3, Onion Odor Associated with Food for Colony A, No Odor Associated with Food for Colony B}

The numerical results are given in Table 3.

During training, a few ants were permanently seen around the presented cues (diffusers). Their numbers varied between 1.08 and 3.67, what was enough for insuring conditioning.

Table 3. Results of experiment 3

\begin{tabular}{|c|c|c|c|c|c|c|}
\hline \multirow{2}{*}{$\begin{array}{l}\text { Experiment } 3 \\
\text { onion vs no odor }\end{array}$} & \multicolumn{3}{|c|}{ Colony A } & \multicolumn{3}{|c|}{ Colony B } \\
\hline & onion & odor + food & no odor & no o & dor + food & onion odor \\
\hline Training at & \multicolumn{6}{|c|}{ Mean numbers of ants approaching the cues } \\
\hline day 1 & & 2.67 & 2.33 & & 3.67 & 1.83 \\
\hline day 2 & & 2.83 & 1.67 & & 3.67 & 1.67 \\
\hline day 3 & & 3.67 & 2.50 & & 3.50 & 1.67 \\
\hline day 4 & & 3.33 & 1.67 & & 1.08 & 1.67 \\
\hline \multicolumn{7}{|c|}{ removal of the cues } \\
\hline Testing after & \multicolumn{6}{|c|}{ Total numbers of ants near the cues and $\%$ of correct responses } \\
\hline $24 \mathrm{~h}$ & 38 & $59.38 \%$ & 26 & 46 & $71.87 \%$ & 18 \\
\hline $48 \mathrm{~h}$ & 40 & $71.43 \%$ & 16 & 75 & $72.12 \%$ & 29 \\
\hline $72 \mathrm{~h}$ & 65 & $72.22 \%$ & 25 & 91 & $87.50 \%$ & 13 \\
\hline $96 \mathrm{~h}$ & 54 & $69.23 \%$ & 24 & 52 & $74.29 \%$ & 18 \\
\hline \multicolumn{7}{|c|}{ removal of the cues; } \\
\hline $24 \mathrm{~h}$ later & 65 & $61.32 \%$ & 41 & 43 & $76.78 \%$ & 13 \\
\hline $48 \mathrm{~h}$ later & 42 & $52.50 \%$ & 38 & 59 & $60.20 \%$ & 39 \\
\hline
\end{tabular}

Ants of colony A were trained to onion odor associated with food (and to no odor associated with no reward), and ants of colony B were trained to no odor associated with food (and to onion odor associated with no reward). The ants could learn the absence of a not pleasant odor, and they did so better when the reward was associated to the absence of this unpleasant odor and not to its presence.

After 24 hours of training, the ants began to respond preferentially to the diffuser associated with food during training. A difference appeared between colony A and colony B. For the former one, having the onion odor associated with food, 38 ants among 64 ones went to that odor, presenting so a score of $59.38 \%$, and a not significant response $\left(\chi^{2}=0.79, \mathrm{df}=1,0.30<\mathrm{P}<0.50\right)$. For colony $\mathrm{B}$, having the absence of odor associated with food, 46 ants among 64 ones went to the empty diffuser, presenting so a score of $71.87 \%$ and a slightly significant response $\left(\chi^{2}=5.55, \mathrm{df}=1,0.01<\mathrm{P}<0.02\right)$. The unpleasant character of the onion may be the cause of such a difference; ants of colony A may be poorly inclined to learn going towards such a unpleasant odor. After 48 hours of training, the ants, essentially those of colony B, more frankly went to the diffuser associated with food during training. Concerning the ants of colony A, 40 among 56 went to the tube diffusing onion odor, what was slightly significant $\left(\chi^{2}=4.53, \mathrm{df}=1,0.02<\mathrm{P}<0.05\right)$ and corresponded to a score of $71.43 \%$. Concerning the ants of colony B, 75 among 104 went to the empty diffuser, a significant response $\left(\chi^{2}=9.79, \mathrm{df}=1,0.001<\mathrm{P}<0.01\right)$ corresponding to a score of $72.12 \%$. After 72 hours of training, the ants' choice of the correct diffuser went on increasing, essentially for colony B. Ants of colony A presented a score of $72.22 \%$, with 65 ants among 90 giving the correct response, a response more significant than that observed after 48 hours of training $\left(\chi^{2}=8.44, \mathrm{df}=1\right.$, $0.001<\mathrm{P}<0.01)$. Ants of colony B reached a score of $87.50 \%$, with 91 ants among 104 going to the empty diffuser, a result also more significant than that observed after 48 hours of training $\left(\chi^{2}=32.31, \mathrm{df}=1, \mathrm{P}<0.001\right)$. After 96 hours of training, the ants' proportion of correct responses no longer increased and even decreased, what is usual for every learning and conditioning (Cammaerts et al., 2011; M. C. Cammaerts \& S. Nemeghaire, 2012; 
Cammaerts, 2012). Ants of colony A made then a score of $69.33 \%, 54$ among 78 ants having been seen near the tube diffusing onion odor, what statistically differed from the random numbers 39 and $39\left(\chi^{2}=5.22, \mathrm{df}=1,0.01\right.$ $<\mathrm{P}<0.02$ ). Ants of colony B made a score of $74.29 \%, 52$ among 70 ants having been seen near the empty tube, what statistically differed from the random numbers 35 and $35\left(\chi^{2}=7.77, \mathrm{df}=1,0.001<\mathrm{P}<0.01\right)$. Once more, the ants better responded when trained to no odor than to onion odor. The two diffusers were then removed from the ants' tray and tests were again performed over time.

Twenty-four hours later, the ants less well responded to the correct diffuser, and a difference appeared again between those having had the onion odor associated with food and those having had the absence of odor so associated. Indeed, 65 ants of colony A among 106 gave the correct response, what was not significant $\left(\chi^{2}=2.26\right.$, $\mathrm{df}=1,0.10<\mathrm{P}<0.20$ ) and corresponded to a score of $61.32 \%$, while 43 ants of colony B among 56 gave the correct response, what was still significant $\left(\chi^{2}=7.54, \mathrm{df}=1,0.001<\mathrm{P}<0.01\right)$ and corresponded to a score of $76.78 \%$. Forty-eight hours after the diffusers removal, the ants no longer significantly responded to the diffusers, but a slight difference still existed between the workers of colony A and those of colony B. For colony A, 42 among 80 workers went to the diffuser containing onion, making the not significant score of $52.5 \%\left(\chi^{2}=0.025\right.$, df $=1,0.80<\mathrm{P}<0.90$ ). For colony $\mathrm{B}, 59$ among 98 workers went to the empty diffuser, making the not significant score of $60.20 \%\left(\chi^{2}=1.67, \mathrm{df}=1, \mathrm{P} \sim 0.20\right)$. It could thus definitively be concluded that ants could comprehend the presence as well as the absence of a not pleasant odor and that they did so better when the absence and not the presence of the odor was associated with the reward.

The ants were then maintained without being trained during one day, and thereafter, since they had fully lost their conditioning to the presence and the absence of onion odor, they were submitted to the following experiment.

3.4 Experiment 4, No Odor Associated with Food for Colony A, Vanilla Odor Associated with Food for Colony B

During training, several ants were permanently observed around the four provided diffusers, their numbers varying between 3.33 and 1.50, what was sufficient to acquire conditioning (Table 4, upper part).

Table 4. Results of experiment 4

\begin{tabular}{|c|c|c|c|c|c|c|}
\hline \multirow{2}{*}{$\begin{array}{l}\text { Experiment } 4 \\
\text { vanilla } v s \text { no odor }\end{array}$} & \multicolumn{3}{|c|}{ Colony A } & \multicolumn{3}{|c|}{ Colony B } \\
\hline & no od & or + food & vanilla odor & vanilla & odor + food & no odor \\
\hline Training at & \multicolumn{6}{|c|}{ Mean numbers of ants approaching the cues } \\
\hline day 1 & & 2.17 & 1.67 & & 2.67 & 1.67 \\
\hline day 2 & & 2.50 & 1.50 & & 3.17 & 2.00 \\
\hline day 3 & & 2.33 & 1.50 & & 2.00 & 1.50 \\
\hline day 4 & & 3.33 & 1.67 & & 2.33 & 2.00 \\
\hline \multicolumn{7}{|l|}{ removal of the cues } \\
\hline Testing after & \multicolumn{6}{|c|}{ Total numbers of ants near the cues and $\%$ of correct responses } \\
\hline $24 \mathrm{~h}$ & 63 & $64.28 \%$ & 35 & 76 & $80.85 \%$ & 18 \\
\hline $48 \mathrm{~h}$ & 52 & $70.27 \%$ & 22 & 66 & $82.50 \%$ & 14 \\
\hline $72 \mathrm{~h}$ & 65 & $70.65 \%$ & 27 & 72 & $87.80 \%$ & 10 \\
\hline $96 \mathrm{~h}$ & 70 & $67.31 \%$ & 34 & 79 & $84.04 \%$ & 15 \\
\hline \multicolumn{7}{|l|}{ removal of the cues; } \\
\hline $24 \mathrm{~h}$ later & 55 & $57.29 \%$ & 41 & 92 & $80.70 \%$ & 22 \\
\hline $48 \mathrm{~h}$ later & 54 & $54.00 \%$ & 46 & 74 & $71.15 \%$ & 30 \\
\hline
\end{tabular}

Ants of colony A were trained to an absence of odor associated with food (and to vanilla odor associated with no reward), and ants of colony B were trained to vanilla odor associated with food (and to no odor associated with no reward). The ants could learn the absence of the odor and did so better when the reward was associated with the presence and not with the absence of the odor.

The numerical results of the successive tests are given in Table 4, lower part. After 24 hours of training, the ants already preferentially went to the diffuser associated with food during training, and did so better when the (pleasant) odor and not its absence was so associated. For colony A, 63 ants among 98 correctly responded, presenting a not yet significant score of $64.28 \%\left(\chi^{2}=3.52, \mathrm{df}=1,0.05<\mathrm{P}<0.10\right)$. For colony B, 76 ants among 94 correctly responded, presenting a highly significant score of $80.85 \%\left(\chi^{2}=18.43, \mathrm{df}=1, \mathrm{P}<0.001\right)$. Such a high score may be due to the very pleasant odor of vanilla and/or to the ants' habituation to the learning of the presence and the absence of an odor (see the discussion section). It should be noted that the orientation of the tray devoted to tests (and thus the outside referential) did not affect the ants' learning of an odor or its absence. After 48 hours 
of training, the ants' response to the correct diffuser increased. For colony A, 52 ants among 74 responded to the empty diffuser, a significant response $\left(\chi^{2}=5.85, \mathrm{df}=1,0.01<\mathrm{P}<0.02\right)$ corresponding to a score of $70.27 \%$. For colony B, 66 ants among 80 responded to the tube diffusing the vanilla odor, a highly significant response $\left(\chi^{2}=\right.$ $17.47, \mathrm{df}=1, \mathrm{P}<0.001$ ) corresponding to a score of $82.50 \%$. Thus, ants which associated the vanilla odor, and not its absence, with food during training went on acquiring more rapidly the required conditioning. After 72 hours of training, the ants' proportion of correct responses still increased, but essentially for colony B. More precisely, 65 ants of colony A among 52 gave the correct response, what was significant $\left(\chi^{2}=7.36, \mathrm{df}=1,0.001<\mathrm{P}<0.01\right)$ and corresponded to a score of $70.65 \%$, while 72 ants of colony B among 82 gave the correct response, what was highly significant $\left(\chi^{2}=25.61, \mathrm{df}=1, \mathrm{P}<0.001\right)$ and corresponded to a score of $87.80 \%$. A last test was made after 96 hours of training. During it, the ants' proportions of correct responses did not enlarge and were even smaller than those presented 24 hours sooner (as generally observed for any conditioning: Cammaerts et al., 2011; M. C. Cammaerts \& S. Nemeghaire, 2012; Cammaerts, 2012). Ants of colony A presented the significant score of $67.31 \%$ with 70 workers among 104 giving the correct response $\left(\chi^{2}=5.73, \mathrm{df}=1,0.01<\mathrm{P}<0.02\right)$. Ants of colony B presented the highly significant score of $84.04 \%$ with 79 workers among 94 giving the correct response $\left(\chi^{2}=\right.$ 23.13, $\mathrm{df}=1, \mathrm{P}<0.001)$. The responses of ants of colonies A and B still differed. At that time, the two diffusers were removed from the colonies' tray, and tests were again performed in the course of the ants' loss of conditioning.

Twenty-four hours later, the ants' choices of the correct diffusers decreased and stayed significant only for colony B. Indeed, 55 ants of colony A among 96 went to the empty diffuser, what was not a significant response $\left(\chi^{2}=\right.$ $0.75, \mathrm{df}=1,0.30<\mathrm{P}<0.50$ ) and corresponded to a score of $57.29 \%$, while 92 ants of colony B among 114 went to the tube diffusing vanilla odor, what was a significant response $\left(\chi^{2}=22.39, \mathrm{df}=1, \mathrm{P}<0.001\right)$ and corresponded to a score of $80.70 \%$. Forty-eight hours after the removal of the diffusers, the proportions of correct responses were still lower. For colony A, it equaled $54.00 \%$ with 54 ants among 100 giving the correct response, what was not significant $\left(\chi^{2}=0.18, \mathrm{df}=1,0.50<\mathrm{P}<0.70\right)$, and for colony $\mathrm{B}$, it equaled $71.15 \%$ with 74 ants among 104 giving the correct response, what was still significant but less than previously $\left(\chi^{2}=8.88, \mathrm{df}=1,0.001<\mathrm{P}<0.01\right)$. The ants of the two colonies lost thus rapidly their olfactory conditioning, and the loss took some more time for ants of colony B simply because they had reached a higher conditioning score.

\section{Discussion-Conclusion}

Having brought to the fore a basic notion of zero, perceptible to the senses (i.e. the notion of 'nothing') in the ant $M$. sabuleti using visual operant conditioning (M. C. Cammaerts \& R. Cammaerts, 2019), we examined if such a notion could also be obtained using operant conditioning to olfactory cues. We found that it was possible and our experimental work allowed bringing some more knowledge on the subject. Let us formulate a few remarks about our results.

1) It was observed that an olfactory conditioning is rapidly lost, a fact we had already previously observed (Cammaerts et al., 2011; M. C. Cammaerts \& S. Nemeghaire, 2012; Cammaerts, 2012).

2) When using a pleasant odor, the basic notion of 'nothing' was more easily acquired when the odor was associated with a reward and the absence of odor not associated with a reward (Table 5). This notion was less easily acquired when it was the inverse, i.e. the absence of odor associated with a reward and the presence of the odor not associated with a reward (Table 5). Such an observation has been independently made three times what confirmed its validity.

Table 5. Comparison of the four successive experiments

\begin{tabular}{llcc}
\hline \multirow{2}{*}{ Odor used, $\mathrm{n}^{\circ}$ of experiment } & \multirow{2}{*}{ Odor character } & \multicolumn{2}{c}{ Score obtained after 48-72 hours of training, the reward being } \\
\cline { 3 - 4 } & & associated to the odor & associated to its absence \\
\hline Lavender, 1 & Pleasant & $73.52 \%$ & $69.12 \%$ \\
Rosemary, 2 & Pleasant & $80.00 \%$ & $75.67 \%$ \\
Onion, 3 & Unpleasant & $72.22 \%$ & $87.50 \%$ \\
Vanilla, 4 & Pleasant & $87.80 \%$ & $70.65 \%$ \\
\hline
\end{tabular}

When the odor was pleasant, the ants' learning score was better when the response to the odor was rewarded (experiments 1,2, and 4). When the odor was unpleasant, the ants' learning score was better when the response to the absence of odor was rewarded (experiment 3). The best learning of an absence of odor was thus obtained by using an unpleasant odor (experiment 3). Concerning the ants' learning of a pleasant odor, an increase of the ants' performance occurred over the experiments 1 to $2(+6.48 \%)$ and 2 to $4(+7.80 \%)$. 
3) When an unpleasant odor was used, the inverse was observed. The ants better acquired the basic notion of 'nothing' when the non existence of an odor was associated with a reward and the unpleasant odor not associated with a reward (Table 5). This notion was less easily acquired when the unpleasant odor was associated with a reward and its absence not associated with a reward (Table 5). However, this later fact has been experimented only once, and should be checked by novel experiments.

4) The notion of the absence of an odor was better acquired when using an unpleasant odor than when using a pleasant one (Table 5). This later fact has been observed three times for the pleasant odor but only once for the unpleasant one. Supplementary experiments should thus be made for checking this last observation.

5) Ants' conditioning ability differed according to the used odor and was of better quality for vanilla odor, the last one used (Table 5). This was not due to the numbers of ants visiting the training sites. It may be due to the kind, the quality and maybe the amount of the odor, which may influence the ants' learning capability, and/or to the ants' habituation to learn the presence and the absence of an odor, i.e. the ants became accustomed to acquire such learning.

6) The location of the diffusers in the trays devoted to tests did not influence the ants' responses. These responses did not thus depend on any outside referential.

7) To our knowledge, it is the first time that operant conditioning was obtained to a 'nothing', to an absence of cue. Up to now, conditioning has always been used and studied by rewarding the animals each time they responded to a given cue (e.g. an object, a light, a sound, an electric shock). We also conducted ants' conditioning in this way since 2004 (e.g. Cammaerts, 2004 a, b, c).

8) As already mentioned here above, and only concerning the learning of the presence of a pleasant odor (Table 5), it may not be ruled out that ants have progressively learned 'to learn the presence and the absence of an odor' (i.e. they may have become habituated to do so, the same brain zone having been each time solicited). This presumption should be submitted to experimentation, but it can already be noted that this is the first observation of such ability in ants, and even in any insects, though it is commonly experienced by humans (personal experience).

9) As a corollary of the here above points 2 and 3, the ants' learning was better when the reward (i.e. the food) was associated with the more pleasant situation (the presence of a pleasant odor, as well as the absence of an unpleasant odor).

Other animals have been shown to be conscious of the absence of something, either at a basic level, perceptible to the senses, or at a more sophisticated level. What is known and easily observable is the perception by dogs of the absence of their master (West \& Young, 2002 and references therein), and in general, the perception of the absence of a leader by the members of a social group (Goldberg, 1998). All the other 'notions of zero' observed in animals concern visual elements (references here below). Birds and more precisely parrots are exceptional in this domain, some ones having a better grasp of the numbers than the average three-year-old child. Also, an African gray parrot may comprehend the mathematical concept of zero, may have an abstract notion of zero, according to the authors of these studies (Pepperberg \& Gordon, 2005). Monkeys have also been experimented as for their potential comprehension of the zero. Experimental results are in favor of their ability in acquiring the notion of zero, though it may be more a concrete than a true abstract notion (Merritt, Rugani, \& Brannon, 2009). Recently, bees have been shown to be able to present a valuable though probably only concrete notion of zero, perceiving it as the lower quantity of a series of different quantities (Howard, Avargues-Weber, Garcia, Greentree, \& Dyer, 2018; Nieder, 2018). Sure that more research on the subject will be done in the future on different animal species.

In fact, the true concept of zero is acquired through four successive steps (Nieder, 2016) which are a basic sensory notion of 'nothing', a thing categorical different from something, a quantitatively empty thing, and finally an abstract notion represented by a symbol. What we obtained in ants was a basic notion of zero, a concrete one, i.e. the first step of the four successive ones leading to the abstract mathematical notion of zero. These four steps are successively presented by humans over their life, by humans over the history of their civilizations, as well as by animals over their biological evolution. Concerning humans, the concept of zero with a given symbol appears rather late in their history, in the Babylonian and the Hindu civilizations, and never in the Roman and the Greek ones (Michelot, 1966). Such a concept also slowly, progressively emerged during a human's live, as emerged the concept of numbers (Fuson, 1988), a child rarely understanding what is a mathematical, abstract, zero before being more than four years old (Michelot, 1966; Hauser, MacNeilage, \& Ware, 1996). 
As for us, we shall come back on the subject with two projects: first the potential ability of ranging numbers of an element and adding them; secondly the potential ability in expecting the occurrence of the following number of a continuous series of numbers of elements.

In conclusion, ants can acquire through experiences the basic sensory perceptible notion of 'nothing', the perception being visual or olfactory. Concerning the present work using olfactory perception, the notion of 'nothing' is more difficult to acquire when the odor is pleasant than when it is unpleasant. Moreover, the notion of 'nothing' is easier acquired by rewarding the response to an odor when it is pleasant, and is easier acquired by rewarding the response to the absence of an odor when it is unpleasant. As a matter of fact, during such a learning, the way according to which the animals are trained, as well as their motivation (their appreciation of the odor for instance) modulate the animals' learning score. Future works will deal with the ants' potential ability in apprehending series of increasing or decreasing quantities.

\section{Conflict of interest}

We affirm having no conflict of interest concerning the potential perception of 'nothing' (a basic concept of zero) by ants.

\section{References}

Biro, D., \& Matsuzawa, T. (2001). Use of numerical symbols by the chimpanzee (Pan troglodytes): Cardinals, ordinals, and the introduction of zero. Animal Cognition, 4(3-4), 193-199. Retrieved from https://link.springer. com/article/10.1007/s100710100086

Cammaerts, M. C. (2004a). Classical conditioning, temporal learning and spatial learning in the ant Myrmica sabuleti. Biologia, 59, 243-256. Retrieved from https://www.researchgate.net/../252999596_Classical_conditioning...

Cammaerts, M. C. (2004b). Operant conditioning in the ant Myrmica sabuleti. Behavioral Processes, 67, 417-425. Retrieved from https://www.ncbi.nlm.nih.gov/pubmed/15518991

Cammaerts, M. C. (2004c). Visual cue generalization and spatial conditioning in the ant Myrmica sabuleti. Biologia, 59, 257-271. Retrieved from http://www.biologia.savba.sk/59_2_04/Cammaerts_MC_257.pdf

Cammaerts, M. C. (2012). Olfactory and visual operant conditioning in the ant Myrmica rubra (Hymenoptera, Formicidae). Bulletin de la Société Royale Belge d'Entomologie, 148, 199-208. Retrieved from http:www.biblio.naturalsciences.be/associated.../bjz/.../cammaerts-p69-78.pdf

Cammaerts, M. C. (2017). Is the largely used analgesic paracetamol without any adverse effects? A study on ants as models. EC Pharmacology and Toxicology, 4(2), 51-68. Retrieved from https://www.ecronicon.com/ ecpt/pdf/ECPT-04-00088.pdf

Cammaerts, M. C. (2018). Can Myrmica rubra ants use tools or learn to use them? International Journal of Biology, 10(1), 12.

Cammaerts, M. C., \& Cammaerts, D. (2014). Comparative outlook over three Myrmica species' biotopes and foragers' know-how. Biologia, 69, 1051-1058.

Cammaerts, M. C., \& Cammaerts, D. (2018). Environmental odors can affect individuals' physiology and ethology (a study on ants as models). Biology, Engineering and Medicine, 3(5), 10.

Cammaerts, M. C., \& Cammaerts, R. (2015a). Are ants (Hymenoptera, Formicidae) capable of self recognition? Journal of Sciences, 5(7), 521-532. Retrieved from https://pdfs.semanticscholar.org/.../a64f817d6ef770e $88449 \mathrm{~d} 9 \mathrm{c} 0 \mathrm{de}$

Cammaerts, M. C., \& Cammaerts, R. (2015b). Ontogenesis of ants' cognitive abilities (Hymenoptera, Formicidae). Advanced Studies in Biology, 7, 335-348 + synopsis: 349-350. Retrieved from http://www.m-hikari.com/ asb/asb2015/asb5-8-2015/5424.html

Cammaerts, M. C., \& Cammaerts, R. (2016). Spatial expectation of food location in an ant on basis of previous food locations (Hymenoptera, Formicidae). Journal of Ethology, 35(1), 9.

Cammaerts, M. C., \& Cammaerts, R. (2019). Ants are at the first stage of the notion of zero. International Journal of Biology, 11(1), 54-65.

Cammaerts, M. C., \& Nemeghaire, S. (2012). Why do workers of Myrmica ruginodis (Hymenoptera, Formicidae) navigate by relying mainly on their vision? Bulletin de la Société Royale Belge d'Entomologie, 148, 42-52. Retrieved from http://www.difusion.ulb.ac.be/vufind//Search/Home?lookfor=/\&page=2160 
Cammaerts, M. C., \& Rachidi, Z. (2009). Olfactory conditioning and use of visual and odorous elements for movement in the ant Myrmica sabuleti (Hymenoptera, Formicidae). Myrmecological News, 12, 117-127. Retrieved from https://myrmecologicalnews.org/cms/index.php?option...

Cammaerts, M. C., Rachidi, Z., \& Cammaerts, D. (2011). Collective operant conditioning and circadian rhythms in the ant Myrmica sabuleti (Hymenoptera, Formicidae). Bulletin de la Société Royale Belge d'Entomologie, 147, 42-154. Retrieved from http:/www.srbe-kbve.be/cm/bulletin

Fuson, K. C. (1988). Children's counting and concepts of number. New York: Springer-Verlag. Retrieved from https://www.springer.com/la/book/9781461283355

Goldberg, J. (1998). Les sociétés animales. Communication, hiérarchie, territoire, sexualité. La bibliothèque du naturaliste. Delachaux \& Nieslé S.A., Lausanne, Paris. Retrieved from http://www.cafe-geo.net/wp-content/ uploads/societes-animales.pdf

Howard, S. R., Avarguès-Weber, A., Garcia, J. E., Greentree, A. D., \& Dyer, A. G. (2018). Numerical ordering of zero in honey bees. Science, 360(6393), 1124-1126. Retrieved from science.sciencemag.org/content/360/63 $93 / 1124$

Hauser, M. D., MacNeilage, P., \& Ware, M. (1996). Numerical representations in primates. Proceedings of the National Academy of Sciences, 93, 1514-1517. Retrieved from www.pnas.org/content/93/4/1514

Merritt, D. J., Rugani, R. R., \& Brannon, E. M. (2009). Empty sets as part of the numerical continuum: Conceptual precursors to the zero concept in rhesus monkeys. Journal of Experimental Psychology General, 138(2), 258269.

Michelot, A. (1966). La notion de zéro. In "L' enfant" a collection directed by Chateau J. Library philosophical Vrin J. Paris. Retrieved from http://www.vrin.fr/book.php?code=9782711605705

Nieder, A. (2016). Representing something out of nothing: The drawing of zero. Trends in Cognitive Sciences, 20(11), 830-842. Retrieved from https://www.ncbi.nlm.nih.gov/pubmed/27666660

Nieder, A. (2018). Honey bees zero in on the empty set. Sciences, 360(6393), 1069-1070.

Pearce, J. M. (2008). Animal learning and cognition, an introduction. East Sussex, USA, Canada. Psychology Press. Retrieved from http://www.worldcat.org/title/animal-learning-cognition-an-introduction/oclc/682223995

Pepperberg, I. M. (1988). Comprehension of "absence” by an African Grey parrot: Learning with respect to questions of same/different. Journal of the Experimental Analysis of Behavior, 50, 553-564. Retrieved from https://www.ncbi.nlm.nih.gov/pmc/articles/PMC1338917/

Pepperberg, I. M. (2006). Grey parrot (Psittacus erithacus) numerical abilities: Addition and further experiments on a zero-like concept. Journal of Comparative Psychology, 120(1), 1-11.

Pepperberg, J. M., \& Gordon, J. D. (2005). Number comprehension by a grey parrot (Psittacus erithacus), including a zero-like concept. Journal of Comparative Psychology, 119(2), 197-209. Retrieved from https:// www.ncbi.nlm.nih.gov/pubmed/15982163

Siegel, S., \& Castellan, N. J. (1989). Nonparametric statistics for the behavioural sciences. Singapore, McGraw-Hill Book Company. Retrieved from https:/www.amazon.com/Sidney-Siegel...Statistics.../B008WDIR6

West, R. E., \& Young, R. J. (2002). Do domestic dogs show any evidence of being able to count? Animal Cognition, 5, 183-186. Retrieved from https://www.ncbi.nlm.nih.gov/pubmed/12357291

\section{Copyrights}

Copyright for this article is retained by the author(s), with first publication rights granted to the journal.

This is an open-access article distributed under the terms and conditions of the Creative Commons Attribution license (http://creativecommons.org/licenses/by/4.0/). 